\title{
Methylphenidate and Dextroamphetamine Abuse in Substance-Abusing
}

\author{
Adolescents
}

Robert J. Williams, PhD'; Leslie A. Goodale, RN²; Michele A. Shay-Fiddler, $\mathrm{MSW}^{2}$; Susan P. Gloster, $\mathrm{BN}^{3}$; Samuel Y. Chang, $\mathrm{MD}^{2}$

1. Addiction Counselling Program; School of Health Sciences; University of Lethbridge

2. Addiction Centre; Foothills Medical Centre; Calgary, Alberta

3. Lethbridge Regional Hospital; Lethbridge, Alberta

Published in 2004 in American Journal on Addictions, 13 (4), 1-9

\author{
Address Correspondence: Dr. Robert Williams \\ Addiction Counselling Program \\ School of Health Sciences \\ University of Lethbridge \\ 4401 University Drive \\ Lethbridge, Alberta \\ T1K 3M4 \\ 403-382-7128 (phone) \\ 403-329-2668 (fax) \\ Robert.Williams@uleth.ca
}




\begin{abstract}
The prevalence of methylphenidate and dextroamphetamine misuse and abuse was examined in 450 adolescents referred for substance abuse treatment. Twenty three percent reported nonmedical use of these substances and six percent were diagnosed as methylphenidate or dextroamphetamine abusers. Abuse was more common in individuals who were out of school and had an eating disorder. Methylphenidate and dextroamphetamine abuse appears to be much less common than abuse of most other substances. It does occur, however, and parents and schools need to exert greater control over the dispensing of these medications. Physicians are advised to prescribe nonstimulant medications (e.g., bupropion) when treating attention deficit hyperactivity disorder in substance-abusing individuals.
\end{abstract}

Key Words: methylphenidate, Ritalin, dextroamphetamine, adolescent, abuse 
Psychostimulants such as methylphenidate (Ritalin ${ }^{\circledR}$ ), dextroamphetamine (Dexedrine ${ }^{\circledR}$ ), and Adderall ${ }^{\circledR}$ are well established as effective treatments for attention deficit hyperactivity disorder ${ }^{1,2,3,4}$. They have potential risks, however, with one of the more important ones being the risk of drug abuse. These medications are classified as Schedule II substances in the Controlled Substances Act, which contains medically prescribed substances with the highest abuse potential and dependence profile.

However, considerable controversy exists about how serious a problem prescribed stimulant abuse actually is. On the one hand, the Council on Scientific Affairs of the American Medical Association concluded that "there is little evidence that stimulant abuse or diversion is currently a major problem, particularly among those with ADHD" ${ }^{5}$. Another review reports "a nearly total absence of methylphenidate abuse reported in methylphenidate-treated children and adolescents in spite of its very widespread application" ${ }^{6}$. An even stronger statement is made in the Practitioners Guide to Psychoactive Drugs for Children \& Adolescents $2^{\text {nd }}$ ed., where it states, "There are no reported individual cases of addiction or serious drug dependence to date with these medications." ${ }^{77}$ Similar sentiments have been echoed elsewhere ${ }^{8,9}$.

On the other hand, the U.S. Drug Enforcement Administration $<D E A>$ has expressed serious concern about methylphenidate being diverted and abused. This was first stated in an October 1995 press release ${ }^{10}$ and background paper ${ }^{11}$ that pointed out that methylphenidate ranks in the top 10 most frequently reported controlled pharmaceuticals stolen from licensed handlers. These concerns were reiterated in congressional testimony to the Subcommittee on Early Childhood, Youth and Families in May 2000. In this testimony the DEA indicated that methylphenidate has a high abuse liability and that the magnitude of methylphenidate diversion and trafficking is comparable to pharmaceutical drugs of similar abuse potential such as morphine ${ }^{12}$.

There is good evidence that a small percentage of adolescents and young adults are using these substances for non-medical purposes. In the national Monitoring the Future survey of high school students, the percentage of seniors reporting non-medical use of Ritalin ${ }^{\circledR}$ in the past year was .1 - .7\% between 1976 and $1993 ; .8-1.2 \%$ between 1994 and 1996; and $2.2-2.8 \%$ between 1997 and $2000^{13}$. A 1998 state-wide survey of Indiana students found that approximately 5\% of students in grades 9-12 reported nonmedical use of Ritalin ${ }^{\circledR}$ in the past year, with $2.5 \%$ reporting non-medical use in the past month $^{14}$. In Canada, $6.3 \%$ of Ontario high school students reported past-year non-medical use of stimulants other than methamphetamine in $1994^{15}$.

However, it is unclear how much actual abuse and dependence is occurring. By definition, substance abuse is a pattern of use leading to clinically significant impairment or distress as manifested by either failure to fulfil major role obligations; recurrent use in physically hazardous situations (e.g. driving); recurrent substance-related legal problems; or serious social or interpersonal problems ${ }^{16}$. Abuse does occur, as evidenced by several case reports of regular use leading to medical problems or death ${ }^{17,18,19,20,21,22,23,24,25,26,27,28}$. Some of these case reports include individuals who were abusing their own prescriptions $^{29,30,9}$.

However, there is very little known about the general prevalence of methylphenidate abuse and dependence. There are a few studies on treatment populations that shed some light on this issue. Haglund and Howerton ${ }^{31}$ found that $59 \%$ of 192 adult patients admitted to a drug abuse treatment program reported non-medical use of methylphenidate at some point, mostly in combination with opiates such as pentazocine $^{31}$. However, only $1.5 \%$ were using methylphenidate on a daily basis. Raskin and Bradford $^{32}$ reported that $18 / 40$ methadone maintenance patients were regular 
intravenous users of methylphenidate. Marsh et al. ${ }^{33}$ found that $10.4 \%$ (24/231) of adolescents referred for an assessment at a community based alcohol/drug treatment facility in South Carolina between 1992 and 1996 reported non-medical use of methylphenidate. No details were provided concerning frequency of use.

Clearly, more research is needed to establish the actual prevalence of prescribed stimulant abuse. The purpose of the present study is to investigate this issue in a group of substance-abusing adolescents with comorbid mental health problems. Our first objective is to determine the prevalence of methylphenidate and dextroamphetamine misuse and abuse in this population. Our second objective is to investigate characteristics that differentiate abusers from nonabusers. This latter information will be particularly useful to physicians in their decisions about when to prescribe stimulants.

Method

The Addiction Centre is located at the Foothills Medical Centre, Calgary, Alberta, Canada. It specializes in the assessment and treatment of substance-abusing adolescents with comorbid psychiatric conditions. It is primarily an outpatient program, but a small percentage of patients are admitted to an affiliated inpatient unit. All adolescents receive a comprehensive 3-4 hour assessment. The assessment begins with an interview using the Adolescent Drug and Alcohol Diagnosis (ADAD), a structured questionnaire with established reliability and validity ${ }^{34,35}$. This interview is followed by urinalysis drug testing, and then the adolescent's family is interviewed. All interviews are conducted by a nurse, social worker or psychologist, while a family physician and an adolescent psychiatrist observe behind a 2-way mirror. The psychiatrist makes diagnoses (current) at the end of the assessment, after reviewing the background file and information presented during the interviews. An extensive 10 to 15- page report is produced from the assessment.

A retrospective file review was conducted of the 450 adolescents seen at the Addiction Centre between January 1993 and May 1999. Each assessment was read by the second and third authors (LG, MS-F) and information was extracted using a coding sheet with the following categories: age, gender, race/ethnicity, school attendance, residency, psychiatric and substance use diagnoses (current), a list of all substances used (lifetime), and whether the adolescent had ever been prescribed methylphenidate or dextroamphetamine (Dexedrine ${ }^{\circledR}$ or Adderall ${ }^{\circledR}$ ). For all individuals who reported nonmedical use of methylphenidate or dextroamphetamine, information was also extracted concerning the method of administration, frequency of use, the length of time using, where they obtained the medication, and reasons for discontinuation.

The sample was divided into methylphenidate/dextroamphetamine abusers and nonabusers to investigate variables that differentiated the groups using a forward stepwise logistic regression. "Abusers" were individuals who received a diagnosis of current methylphenidate or dextroamphetamine abuse at the time of the assessment. "Non-abusers" were individuals who did not receive a diagnosis of current methylphenidate or dextroamphetamine abuse (although some of these individuals may have used these substances occasionally for non-medical purposes at some point in their lives ("misusers") and some may have had a past history of methylphenidate or dextroamphetamine abuse).

\section{$\underline{\text { Results }}$}

Age range of the sample was 12 to 18 years, with an average of 15.4. Fifty-two percent were male, 82 percent were Caucasian, 69 percent were attending school, and 78 percent were living at home. The most common psychiatric diagnoses were Conduct 
Disorder (26\%), Major Depression (26\%), Attention-Deficit Hyperactivity Disorder (25\%), Oppositional Defiant Disorder (18\%), Post-Traumatic Stress Disorder (17\%), Dysthymia (15\%), Substance-Induced Mood Disorder (11\%), and Learning Disability (10\%).

Twenty three percent (105/450) of adolescents reported non-medical use of either methylphenidate or dextroamphetamine at some point in their lives ("Misusers"). Of these 105 adolescents, 92 reported non-medical use of methylphenidate, 7 reported nonmedical use of dextroamphetamine (Dexedrine), and 6 reported non-medical use of both. The median number of times used was 3 (range $1-700$ ), and the median length of time used was 26 days (range 1 day -3 years). Of the 87 adolescents ever prescribed methylphenidate or dextroamphetamine, $38 / 87$ (44\%) reported non-medical use.

Six percent (26/450) of the sample was diagnosed as current methylphenidate or dextroamphetamine abusers ( 23 were methylphenidate abusers and 3 were methylphenidate and dextroamphetamine (Dexedrine) abusers). The most common method of administration was crushing tablets and taking the drug intranasally. The median number of times used was 80 (range 21 - 700). The median length of time using was 120 days (range 21 days - 3 years). The median frequency of use was daily (range 3 times/week - 5 times/day). Twenty-two individuals reported where they obtained the medication: $41 \%$ (9/22) obtained it from their own prescription; $23 \%(5 / 22)$ from the street; $23 \%(5 / 22)$ from a friend's prescription; and $15 \%(4 / 26)$ from a sibling's prescription.

For comparison purposes, Table 1 lists the reported lifetime use and current abuse of all substances. As can be seen, methylphenidate and dextroamphetamine were both the $7^{\text {th }}$ most commonly used and abused substances.

<Insert Table 1 here>

An SPSS forward stepwise logistic regression investigated characteristics differentiating individuals with diagnosed methylphenidate/dextroamphetamine abuse and those without this diagnosis. Variable entry order was determined by the size of the Wald statistic, with a minimum entry level of $p=.05$ and a removal level of $p=.10$. Thirtytwo demographic, psychiatric, and substance use predictor variables were used. After deletion of 5 cases with missing values, data from 445 adolescents were available for analysis: 26 abusers and 419 nonabusers.

Maximal discrimination between the groups occurred with a constant and only two predictor variables: being in school and having an eating disorder. Abusers were significantly more likely to be out of school and to have an eating disorder. A test of the full model with the two predictors against a constant-only model was statistically reliable, $\chi^{2}(2, \underline{N}=445)=12.1, p<.005$, indicating that the two predictors reliably distinguished between abusers and nonabusers. The variance accounted for was small, however, with Nagelkerke R squared $=.075$. Overall prediction success was $93.8 \%$. Table 2 lists the demographic and psychiatric characteristics of the two groups as well as the Wald statistics for each of these variables. Table 3 lists the substance use characteristics of the two groups and the Wald statistics for these variables.

$<$ Insert Table 2 here>

$<$ Insert Table 3 here>

\section{Discussion}

The present study found that $23 \%$ of adolescents referred for a substance-abuse assessment at an outpatient clinic reported non-medical use of methylphenidate or dextroamphetamine at some point in their lives. Most of these individuals misused these substances a few times on a few occasions. However, a small portion of the sample used on a much more frequent and sustained basis. Six percent of the total sample was 
diagnosed as methylphenidate or dextroamphetamine abusers at the time of the assessment.

Our results indicate that for this population, prescription stimulant abuse is neither at crisis proportions nor is it a nonexistent problem. It is clear that prescribed stimulants are misused and abused. However, it is also clear that the misuse and abuse is not occurring on the same scale as other substances. Methylphenidate and dextroamphetamine were the seventh most commonly used substances after alcohol, cannabis, hallucinogens, cocaine or crack, over-the-counter drugs (non-medical use), and methamphetamine; and the seventh most commonly abused substances after alcohol, cannabis, hallucinogens, cocaine or crack, inhalants, and methamphetamine. To further put this in perspective, although there were 1,478 emergency room mentions of methylphenidate in the Drug Abuse Warning Network in 1999, there were 168,763 mentions of cocaine ${ }^{5}$ (although it should be noted these statistics refer to all mentions, not just adolescents).

The rate of methylphenidate/dextroamphetamine misuse is roughly four times higher than the rate of abuse. It is fairly typical that a much higher percentage of individuals experiment with a drug than abuse the drug. However, it is worth noting that in the present study only phencyclidine, over-the-counter drugs, minor tranquilizers, and barbiturates had a higher ratio of misusers to abusers. Anecdotal evidence suggests that although methylphenidate is widely available and fairly inexpensive, it is not often a first choice of adolescent substance users because of its status as a synthetic medication. It should also be noted that although methylphenidate can produce comparable levels of "high" or "rush" compared to cocaine ${ }^{36}$, it is cleared from the brain much more slowly, which tends to be associated with less subsequent craving ${ }^{37}$.

There were very few demographic, psychiatric or substance use characteristics significantly differentiating abusers from nonabusers. The exception to this was school attendance and having a concurrent eating disorder. Abusers were significantly less likely to be attending school ( $41 \%$ attending versus $71 \%$ of nonabusers). This may be because methylphenidate/dextroamphetamine abuse makes ongoing school attendance more difficult. Or, it may be that methylphenidate/dextroamphetamine abuse and school absenteeism are both manifestations of more severe problems. The increased likelihood of abusers having an eating disorder ( $11 \%$ versus $2 \%$ of nonabusers) is likely because the decreased appetite and weight loss associated with these medications makes them appealing to individuals trying to control their weight.

\section{Limitations}

The main limitation of this study is that the sample is not representative of substance-abusing adolescents generally, as it contains a greater proportion of duallydiagnosed individuals. Roughly $95 \%$ of individuals in the present study had a co-occurring psychiatric disorder, compared to approximately $50 \%$ in the general population of substance-abusing adolescents ${ }^{38}$. However, in all other respects the demographics of our sample appears to be similar to what is found in the general adolescent treatment population $^{39,40}$ and in the general adolescent substance-abusing population ${ }^{41}$. The present study also does not address the abuse of these substances in substance-using adults, which may be much higher or lower. A final limitation is that ascertainment of substance use was based primarily on self-report. Although the accompanying urinalysis helped ensure valid report at the time of the assessment, it did not ensure validity of the historical reports given. 


\section{Clinical Implications}

Psychostimulants are effective treatments for attention deficit hyperactivity disorder. However, they do have risks, with one of the more important ones being the risk of misuse and abuse. Although not directly tested, the present results suggest that the most important risk factor for methylphenidate/dextroamphetamine misuse and abuse is the abuse of other substances (i.e., only $2 \%$ of senior high school students in the latest Monitoring the Future study misused prescribed stimulants versus $23 \%$ of substance abusing adolescents in the present study). Substance abusing adolescents who are out of school and/or have a concurrent eating disorder appear to have an even higher risk.

Thus, routine screening for substance abuse and eating disorders is a sensible precaution that should occur before any medication is prescribed. Furthermore, considering the efficacy of certain non-stimulant medications for attention deficit hyperactivity (e.g., bupropion) ${ }^{42,43}$, it is recommended that non-stimulant medications be used as a first line pharmacological treatment for these higher risk groups.

Although physicians need to be cautious about to whom they prescribe psychostimulants, parents have an even more important role to play. In the present study, roughly three-quarters of the methylphenidate and dextroamphetamine abused came from the adolescent's own prescription or the prescription of a friend or sibling. The risk of psychostimulant abuse could be substantially reduced if parents became more aware of the abuse potential of prescription stimulants and exerted greater control over the dispensing of these medications. 
$\underline{\text { References }}$

1. Findling R, Dogin J. Psychopharmacology of ADHD: children and adolescents. J Clin Psychiatry. 1998;59(Suppl 7):42-49.

2. Greenhill L, Halperin J, Abikoff H. Stimulant medications. J Am Acad Child Adoles Psychiatry. 1999;38:503-512.

3. MTA Cooperative Group. A 14-Month randomized clinical trial of treatment strategies for attention-deficit/hyperactivity disorder. Arch Gen Psychiatry. 1999;56:1073-1086.

4. Spencer T, Biederman J, Wilens T. Pharmacotherapy of attention deficit hyperactivity disorder. Child Adolesc Psychiatr Clin N Am. 2000; 9:77-97.

5. Goldman L, Genel M, Bezman R, Slanetz P. Diagnosis and treatment of attentiondeficit/hyperactivity disorder in children and adolescents. J Am Med Assoc. 1999;279:1100-1107.

6. Klein R, Wender P. The role of methylphenidate in psychiatry. Arch Gen Psychiatry. 1995;52:429-433.

7. Werry J, Aman M. Practitioners Guide to Psychoactive Drugs for Children \& Adolescents. $2^{\text {nd }}$ ed. New York,NY: Plenum; 1999

8. Barkley R. Attention-Deficit Hyperactivity Disorder. $2^{\text {nd }}$ ed. New York,NY: Guilford;1998.

9. Jaffe S. Intranasal abuse of prescribed methylphenidate by an alcohol and drug abusing adolescent with ADHD. J Am Acad Child Adoles Psychiatry. 1991; 30:773775.

10. Drug Enforcement Administration. Methylphenidate: DEA Press Release. Washington, DC: DEA; 1995a, October 20.

11. Drug Enforcement Administration. Methylphenidate (A background paper). Washington, DC: Drug and Chemical Evaluation Section, Office of Diversion Control, DEA; 1995b, October.

12. Drug Enforcement Administration. DEA Congressional Testimony by Terrance Woodworth before the Committee on Education and the Workforce: Subcommittee on Early Childhood, Youth and Families. World Wide Web URL: http://www.usdoj.gov/dea/pbs/cngrtest/ct051600.htm. May 16, 2000.

13. Johnston L, O'Malley P, Bachman J. Monitoring the Future National Survey Results on Drug Use, 1975-2000. Volume I: Secondary School Students (NIH Publication No. 01-4924). Bethesda, MD: National Institute on Drug Abuse; 2001

14. Indiana Prevention Resource Center Survey. Alcohol, Tobacco, and Other Drug Use by Indiana Children and Adolescents. Bloomington, Indiana: Indiana University; 1998

15. Addiction Research Foundation. The Ontario Study Drug Use Survey: 1977-1995. Toronto, Ontario: ARF; 1995

16. American Psychiatric Association. Diagnostic and Statistical Manual for the Classification of Mental Disorders. $4^{\text {th }}$ ed. Washington, DC: American Psychiatric Press; 1994.

17. Elenbass $\mathrm{R}$, Waeckerie J, McNabney W. Abscess formation as a complication of parenteral methylphenidate abuse. JACEP. 1976; 5: 977-980.

18. Gunby P. Methylphenidate abuse produces retinopathy. J Am Med Assoc. 1979; 241:546.

19. Hahn H, Schweid A, Beaty H. Complications of injecting dissolved methylphenidate tablets. Arch Intern Med. 1969;123:656.

20. Levine B, Caplan Y, Kauffman G. Fatality resulting from methylphenidate overdose. $J$ Anal Toxicol. 1986;10:209-210. 
21. Lundquest D, Young W, Edland J. Maternal death associated with intravenous methylphenidate (Ritalin) and pentazocine (Talwin). J Forensic Sci. 1987;32:798801.

22. Massello W, Carpenter D. A fatality due to the intranasal abuse of methylphenidate (Ritalin). J Forensic Sci. 1999;44:220-221.

23. Mehta $H$, Murray $B$, Loludice $T$. Hepatic dysfunction due to intravenous abuse of methylphenidate hydrochloride. J Clin Gastroenterol. 1984;6:149-151.

24. Sherman C, Hudson L, Pierson D. Severe precocious emphysema in intravenous methylphenidate (Ritalin) abusers. Chest. 1987;92:1085-1087.

25. Spensley J, Rockwell S. Psychosis during methylphenidate abuse. N Eng J Med. 1972;286:880-881.

26. Stecyk O, Loludice T, Demeter S, Jacobs J. Multiple organ failure resulting from intravenous abuse of methylphenidate hydrochloride. Ann Emerg Med. 1985;14:597599.

27. Wolf J, Fein A, Fehrenbacher L. Eosinophilic syndrome with methylphenidate abuse. Ann Intern Med. 1978;89:224-225.

28. Zemplenyi J, Colman M. Deep neck abscesses secondary to methylphenidate (Ritalin) abuse. Head \& Neck Surgery. 1984;6:858-860.

29. Garland E. Intranasal abuse of prescribed methylphenidate. J Am Acad Child Adoles Psychiatry. 1998;37:573-574.

30. Goyer P, Davis G, Rapoport J. Abuse of prescribed stimulant medication by a 13 year old hyperactive boy. J Am Acad Child Adoles Psychiatry. 1979;18.21-29.

31. Haglund R, Howerton L. Ritalin: Consequences of abuse in a clinical population. International Journal of the Addictions. 1982;17:349-356.

32. Raskin M, Bradford T. Methylphenidate abuse and methadone maintenance. Diseases of the Nervous System. 1975;36:9-12.

33. Marsh L, Key J, Payne T. Methylphenidate misuse in substance abusing adolescents. Journal of Child \& Adolescent Substance Abuse. 2000;9:1-14.

34. Friedman $A$, Utada $A$. A method for diagnosing and planning the treatment of adolescent drug abusers: The Adolescent Drug Abuse Diagnosis (ADAD) instrument. J Drug Educ. 1989;19:285-312.

35. Leccese $M$, Waldron $\mathrm{H}$. Assessing adolescent substance use: A critique of current measurement instruments. J Subst Abuse Treat. 1994;11:553-563.

36. Kollins S, MacDonald E, Rush C. Assessing the abuse potential of methylphenidate in nonhuman and human subjects: a review. Pharmacol Biochem Behav. 2001;68:611627.

37. Volkow N, Ding Y, Fowler J, et al. Is methylphenidate like cocaine? Studies on their pharmacokinetics and distribution in the human brain. Arch Gen Psychiatry. 1995;52:456-463.

38. Greenbaum P, Foster-Johnson L, Petrila A. Co-occurring addictive and mental disorders among adolescents: Prevalence research and future directions. Am J Orthopsychiatry. 1996;66:52-60.

39. U.S. Department of Health and Human Services. National Admissions to Substance Abuse Treatment Services: The Treatment Episode Data Set (TEDS) 1992-1995.

Substance Abuse and Mental Health Services Administration. Author; 1995.

40. Williams R, Chang S. A comprehensive and comparative review of adolescent substance abuse treatment outcome. Clinical Psychology: Science and Practise. 2000; 7:138-166.

41. U.S. Department of Health and Human Services. The Prevalence and Correlates of 
Treatment for Drug Problems. Substance Abuse and Mental Health Services Administration. DHHS Publication No. (SMA) 97-3135. Author; 1997.

42. Biederman J, Spencer T. Non-stimulant treatments for ADHD. Eur Child Adolesc Psychiatry. 2000;9 (Suppl 1):151-159.

43. Popper $\mathrm{C}$. Pharmacologic alternatives to psychostimulants for the treatment of attention-deficit/hyperactivity disorder. Child Adolesc Psychiatr Clin N Am. 2000;9:605-46. 
Table 1

Lifetime Use and Current Abuse of Substances for the Entire Sample

\begin{tabular}{|c|c|c|}
\hline & $\begin{array}{c}\text { Lifetime } \\
\text { Use }\end{array}$ & $\begin{array}{c}\text { Current } \\
\text { Abuse }\end{array}$ \\
\hline Alcohol & $98 \%$ & $80 \%$ \\
\hline Cannabis & $96 \%$ & $85 \%$ \\
\hline Hallucinogens & $79 \%$ & $46 \%$ \\
\hline Cocaine or Crack & $38 \%$ & $18 \%$ \\
\hline Over-the-Counter Drugs (non-medical use) & $27 \%$ & $6 \%$ \\
\hline Methamphetamine & $24 \%$ & $7 \%$ \\
\hline $\begin{array}{r}\text { Methylphenidate/Dextroamphetamine (non-medical } \\
\text { Isca) }\end{array}$ & $23 \%$ & $6 \%$ \\
\hline Inhalants & $17 \%$ & $9 \%$ \\
\hline Prescription Opiates (non-medical use) & $17 \%$ & $6 \%$ \\
\hline Phencyclidine & $17 \%$ & $4 \%$ \\
\hline Nonprescription Opiates & $9 \%$ & $4 \%$ \\
\hline Minor Tranquilizers (non-medical use) & $7 \%$ & $1 \%$ \\
\hline Barbiturates & $2 \%$ & $0 \%$ \\
\hline
\end{tabular}


Table 2

Demographic and Psychiatric Characteristics of Methylphenidate/Dextroamphetamine Abusers and Non-Abusers

\begin{tabular}{|c|c|c|c|}
\hline & $\begin{array}{c}\text { Abusers } \\
(n=26)\end{array}$ & $\begin{array}{c}\text { Non- } \\
\text { Abusers } \\
(\mathrm{n}=424)\end{array}$ & $\begin{array}{c}\text { Wald } \\
\text { Statistic }^{1}\end{array}$ \\
\hline In school & $41 \%$ & $71 \%$ & 7.3 \\
\hline Caucasian & $74 \%$ & $82 \%$ & 1.7 \\
\hline Male & $43 \%$ & $52 \%$ & 1.3 \\
\hline Living at home & $77 \%$ & $78 \%$ & .3 \\
\hline Age & 15.6 & 15.4 & .2 \\
\hline Eating Disorder & $11 \%$ & $2 \%$ & 8.4 \\
\hline $\begin{array}{r}\text { Substance-Induced Mood } \\
\text { Disnrter }\end{array}$ & $21 \%$ & $11 \%$ & 3.2 \\
\hline Major Depression & $43 \%$ & $25 \%$ & 2.7 \\
\hline ADHD & $36 \%$ & $24 \%$ & 2.1 \\
\hline Dysthymia & $7 \%$ & $15 \%$ & 1.3 \\
\hline Learning Disability & $4 \%$ & $10 \%$ & 1.1 \\
\hline Bipolar & $4 \%$ & $1 \%$ & .5 \\
\hline Mental Retardation & $0 \%$ & $2 \%$ & .5 \\
\hline Schizophrenia & $0 \%$ & $1 \%$ & .4 \\
\hline Panic Disorder & $0 \%$ & $1 \%$ & .4 \\
\hline Generalized Anxiety & $0 \%$ & $2 \%$ & .3 \\
\hline Conduct Disorder & $25 \%$ & $26 \%$ & .2 \\
\hline Oppositional Defiant Disorder & $18 \%$ & $18 \%$ & .1 \\
\hline Post-Traumatic Stress Disorder & $18 \%$ & $17 \%$ & 0 \\
\hline
\end{tabular}

${ }^{1}$ Wald statistics following entry of the two significant variables into the forward stepwise logistic regression. All Wald statistics were nonsignificant unless otherwise noted. 
Table 3

Concurrent Substance Abuse by Methylphenidate/Dextroamphetamine Abusers and NonAbusers

\begin{tabular}{rccc} 
& $\begin{array}{c}\text { Abusers } \\
(\mathrm{n}=26)\end{array}$ & $\begin{array}{c}\text { Non- } \\
\text { Abusers } \\
(\mathrm{n}=424)\end{array}$ & $\begin{array}{c}\text { Wald }^{1} \\
\text { Statistic }\end{array}$ \\
\hline Phencyclidine Abuse & $11 \%$ & $4 \%$ & 3.2 \\
Nonprescription Opiate Abuse & $11 \%$ & $4 \%$ & 2.8 \\
Methamphetamine Abuse & $14 \%$ & $6 \%$ & 2.4 \\
Prescription Opiate Abuse & $14 \%$ & $6 \%$ & 1.9 \\
Other Prescription Drug Abuse & $4 \%$ & $3 \%$ & 1.4 \\
Cocaine/Crack Abuse & $32 \%$ & $18 \%$ & .8 \\
Inhalant Abuse & $4 \%$ & $10 \%$ & .7 \\
Hallucinogen Abuse & $54 \%$ & $46 \%$ & .3 \\
Over-the-Counter Drug Abuse & $4 \%$ & $6 \%$ & .3 \\
Minor Tranquilizer Abuse & $0 \%$ & $1 \%$ & .2 \\
Cannabis Abuse & $85 \%$ & $85 \%$ & 0 \\
Alcohol Abuse & $79 \%$ & $81 \%$ & 0 \\
\# Substances Abused & 3.1 & $0 \%$ & 0 \\
\hline Barbiturate Abuse & $0 \%$ & 2.7 & 1.6 \\
\hline
\end{tabular}

${ }^{1}$ Wald statistics following entry of the two significant variables into the forward stepwise logistic regression. All Wald statistics were nonsignificant unless otherwise noted. 